\title{
ACANTHOSIS NIGRICANS IN THE HEAD AND NECK REGION
}

\author{
James A. Fasunla M.B.Ch.B, Gbolagunte T. Ijaduola FWACS \\ Department of Otorhinolaryngology, University College Hospital, Ibadan.
}

Corresponding Author:

Dr. Ayotunde J. Fasunla

Senior Registrar

Department of Otorhinolaryngology,

University College Hospital,

PMB 5116, Queen Elizabeth road,

Ibadan, Nigeria.

Telephone number: 08033740220

Email address: ayofasunla@yahoo.com

\begin{abstract}
Background: The sudden appearance of acanthosis nigricans on the skin of an individual is highly suggestive of an underlying clinical disease. However, there is no information on its possible association with head and neck disease in our environment.

Objective: To determine the prevalence of acanthosis nigricans and identifying the underlying associated medical and oncologic factor in an Otorhinolaryngologic, head and neck practice.

Method: This was a 12-month prospective study of patients seen at Otorhinolaryngology department of University College Hospital, Ibadan. Relevant clinical, anthropometric and biochemical information were obtained with an interviewer assisted questionnaire and data analyzed using descriptive statistics.

Results: Of 764 patients, 85(11.13\%) had head and neck malignancies, $15(1.96 \%)$ had diabetes mellitus in addition to the Otorhinolaryngologic, head and neck diseases. The body mass index values for male and female ranged from $18.26-25.68 \mathrm{~kg} / \mathrm{m}^{2}$ and $17.94-30.25 \mathrm{~kg} / \mathrm{m}^{2}$ respectively. Only two patients, one with nasopharyngeal cancer and the other with obesity in addition to chronic rhinosinusitis had acanthosis nigricans.

Conclusion: Acanthosis nigricans is not common among Otorhinolaryngologic patients in our clinical setting with a prevalence of 0.003 . Nevertheless, its presence should herald the suspicion of an underlying metabolic or oncologic disease.
\end{abstract}

Keywords: Acanthosis Nigricans, Otorhinolaryngology, Head, Neck

\section{INTRODUCTION}

Acanthosis nigricans is a skin disorder characterized by dark, thick, velvety plaque of the skin which usually occurs in body folds but may involve other parts of the body ${ }^{1}$. It is commonly seen on the neck, in the armpit and groin. It could also be found on the elbow, knee and knuckles ${ }^{2,3,4}$. It is a disorder found commonly among the African descents with darker skin pigmentation. It is a disorder that may begin at any age and has no gender differences ${ }^{5}$. It can affect otherwise healthy people or be associated with underlying medical disease ${ }^{3}$. Although, the actual cause is unknown, it is most likely caused by factors that stimulate epidermal keratinocyte and dermal fibroblast proliferation. There are two broad categories of acanthosis nigricans namely; benign and malignant. In the benign form of acanthosis nigricans, some cases are genetically inherited. The mode of inheritance has not been established, however, autosomal recessive or polygenic inheritance has been proposed ${ }^{6}$. Acanthosis nigricans is most commonly associated with being overweight $\left(B M I>25 \mathrm{~kg} / \mathrm{m}^{2}\right)$ and it is frequently found in people with diabetes ${ }^{7-10}$. The stimulating factor is probably insulin or an insulin-like growth factor that incites the epidermal cell propagation. Hyperinsulinemia results in binding of insulin to insulinlike growth factor receptors on keratinocytes and fibroblasts, with resultant hyperplasia of the skin ${ }^{11}$. Insulin resistance due to obesity underlies the hyperinsulinemia in obesity-associated acanthosis nigricans ${ }^{12,13}$. Sometimes acanthosis nigricans is due to other forms of endocrine (glandular) disorder such as polycystic ovary syndrome, acromegaly, pituitary or adrenal adenomas, and cushing syndrome ${ }^{14}$. It could also result from the use of exogenous drugs like hormones (contraceptive pills), cytotoxics, steroid, large dose of niacin etc ${ }^{1,15}$. The malignant form is by far less common and the patients with this type tend to be thin and older than 40 years of age, and their eruption is usually of recent origin ${ }^{16,17}$. The stimulating factor in malignant acanthosis nigricans is hypothesized to be a substance secreted either by the tumor or in response to the tumor. Transforming growth factoralpha is structurally similar to epidermal growth factor and it has been implicated ${ }^{18-20}$. Acanthosis nigricans is rarely associated with a tumor and if it does, unusually severe. Development of acanthosis nigricans may be the first clue to an underlying neoplastic process in an otherwise healthy adult. Ninety percent of the neoplasms responsible for the development of acanthosis nigricans originate in the abdomen ${ }^{21}$. Nonetheless, there is no information on acanthosis nigricans among the head and neck patients in our environment. Hence, our aim is to describe the pattern of presentation of acanthosis nigricans, to determine its prevalence and to identify the underlying associated medical and oncologic factors among head and neck patients managed at department of Otorhinolaryngology, University College Hospital, Ibadan. 


\section{MATERIALS AND METHOD}

A prospective study of all patients that presented to the ENT clinic and ward of University College Hospital, Ibadan from August 2005 to August 2006 was carried out. An understood informed consent was obtained from all the patients that participated in the study. A structured interview assisted questionnaire was used to collect the biodata (Age, Sex, and Nationality), Ear, nose and throat disease, history of presence of a thick dark area on the skin, and the duration for which it had been noticed. History of diabetes mellitus, malignancy, and use of cytotoxics, hormonal drugs (oral contraceptives) and steroids were obtained. All the patients had their head and neck region, armpits, breasts, elbow, groin, knees and knuckles examined for presence of acanthosis nigricans. The weight $(\mathrm{Kg})$ and height $(\mathrm{m})$ of the patients were measured to determine their body mass index. All the patients with history of diabetes mellitus had fasting plasma glucose done. Data were analyzed using descriptive statistics.

\section{RESULTS}

There were seven hundred and sixty four patients; 347 $(45.42 \%)$ males and $417(54.58 \%)$ females with age ranged between 3 and 63 years old and overall mean age of 47.78 and standard deviation of 21.08 (Table 1). There were $85(11.13 \%)$ patients with head and neck malignancies, $47(55.29 \%)$ males and 38(44.71\%) females (Table 2). Forty six $(54.12 \%)$ patients had sinonasal cancer, $17(20 \%)$ had nasopharyngeal cancer, $3(3.53 \%)$ had ear cancer, $12(14.12 \%)$ had laryngeal cancer. Three $(3.53 \%)$ patients had metastatic neck disease. One of the female patients with nasopharyngeal cancer had acanthosis nigricans around the neck folds.

\begin{tabular}{|l|l|l|}
\hline Age range(YRS) & Frequency & Percentage (\%) \\
\hline $1-10$ & 69 & 9.03 \\
\hline $11-20$ & 67 & 8.77 \\
\hline $21-30$ & 169 & 22.12 \\
\hline $31-40$ & 229 & 29.97 \\
\hline $41-50$ & 163 & 21.33 \\
\hline $51-60$ & 58 & 7.59 \\
\hline $61-70$ & 9 & 1.19 \\
\hline Total & 764 & 100.00 \\
\hline
\end{tabular}

Table 1: Age range distribution of participants

\begin{tabular}{|l|l|l|}
\hline Site of Tumour & Frequency & $\begin{array}{l}\text { Presence/ } \\
\text { Absence of } \\
\text { AN }\end{array}$ \\
\hline Sinonasal & $16(18.82 \%)$ & - \\
\hline Larynx & $18(21.18 \%)$ & - \\
\hline Nasopharynx & $24(28.23 \%)$ & 1 \\
\hline Ear & $3(3.53 \%)$ & - \\
\hline Metastatic neck disease & $4(4.71 \%)$ & - \\
\hline Oropharynx & $3(3.53 \%)$ & - \\
\hline Mandible & $6(7.06 \%)$ & - \\
\hline Oral Cavity & $3(3.53 \%)$ & - \\
\hline Hypopharynx & $5(5.88 \%)$ & - \\
\hline Parotid & $3(3.53 \%)$ & - \\
\hline Total & $85(100.00 \%)$ & 1 \\
\hline
\end{tabular}

Table 2: Distribution of head and neck malignancies and acanthosis nigricans

There were $15(1.96 \%)$ patients, Five $(33.33 \%)$ males and $10(66.67 \%)$ female with associated diabetes mellitus in addition to the head and neck lesion. All had their fasting blood sugar checked and were all within normal limit. Two patients with diabetes mellitus had associated head and neck malignancy (nasopharyngeal and laryngeal cancer). The body mass index values for male ranged from $18.26-25.68 \mathrm{~kg} /$ $\mathrm{m}^{2}$ while that of female ranged from 17.94-30.25 $\mathrm{kg} / \mathrm{m}^{2}$. Sixteen $(2.09 \%)$ of the patients were overweight with body mass index $>25 \mathrm{~kg} / \mathrm{m}^{2}$ (8males and 8 females). One of the female obese patients $\left(B M I=30.25 \mathrm{~kg} / \mathrm{m}^{2}\right.$ ) with chronic rhinosinusitis had acanthosis nigricans in her armpit and under the breast folds. Thirteen $(6.60 \%)$ female patients had history of usage of contraceptive pills for average period of 4 months (range $2-9$ months). Twenty-one $(2.75 \%)$ of the patients had history of treatment with cytotoxic drugs. The head and neck disease distribution in our patients is shown in Table 3.

\section{Discussion}

Acanthosis nigricans is a rare disease. It is not in itself dangerous but it can be associated with a potentially dangerous diseases. The actual prevalence of the disease is unknown. Various researchers had reported different prevalence of the disease in different regions of the world ${ }^{7,22}$. Acanthosis nigricans is much more common in people with darker skin pigmentation ?. The prevalence in whites is less than $1 \%$. In Hispanics, the 
prevalence is $5.5 \%$, and, in African Americans, the prevalence is the highest at $13.3 \%{ }^{7,9,22}$. However, in this study, the prevalence of acanthosis nigricans among head and neck patients was $0.003 \%$. This low prevalence rate might be due to the fact that most of our patients were without the previously documented associated factor of acanthosis nigricans. In addition, there was non availability of a similar study among head and neck patients for comparison. A previous study had reported 2 out of 12,000 patients with internal malignancy having acanthosis nigricans ${ }^{21}$. In our series, only one patient with head and neck malignancy had acanthosis nigricans. Although, no gender inequality had been reported, the two cases of acanthosis nigricans seen in this study were female. before they were seen and recruited into this study. This is a good enough time for the skin lesion to have cleared if it was actually present on their skin.

In conclusion, Acanthosis nigricans is a rare dermatologic condition in our Otorhinolaryngologic practice with a prevalence of 0.003 . Its identification on the skin of patients presenting to the Otorhinolaryngologic clinic must not be casually dismissed without searching for possible associated underlying metabolic or oncologic disorder. The early detection of an underlying disease will in no doubt result in a better treatment outcome.

\begin{tabular}{|l|c|c|}
\hline $\begin{array}{l}\text { Otorhinolaryngologic, head } \\
\text { and neck disease }\end{array}$ & Frequency & $\begin{array}{l}\text { No. of patients with } \\
\text { Acanthosis Nigricans }\end{array}$ \\
\hline Otology & $354(46.34 \%)$ & 2 \\
\hline Rhinology & $247(32.33 \%)$ & - \\
\hline Laryngology, Head and Neck & $163(21.33 \%)$ & 2 \\
\hline Total & $764(100 \%)$ & 2 \\
\hline
\end{tabular}

Table 3: Otorhinolaryngologic, head and neck disease distribution and Acanthosis Nigricans

Acanthosis nigricans can occur at any age; however, the malignant type is usually seen above the age of 40 years ${ }^{18-20,23}$. This is in agreement with what was found in this study as our patient with nasopharyngeal tumor who had acanthosis nigricans was 42 years old. The presentation of acanthosis nigricans is common at the body folds especially on the neck, in the armpit and groin. This is the case in this study as it was found exclusively around the patient's neck fold.

The benign type of acanthosis nigricans is commoner than the malignant type. Normal range of BMI according to WHO are $18.5-24.9 \mathrm{~kg} / \mathrm{m}^{2}$. Overweight is e" $25 \mathrm{~kg} / \mathrm{m}^{2}$. Obese individual has a BMI of $>30 \mathrm{~kg} / \mathrm{m}^{2}$ and this is associated with a great morbidity. Sixteen $(2.09 \%)$ of our patients in this study were overweight but only one obese patients had acanthosis nigricans in her armpit and under the breast folds. The head and neck disease in this patient was chronic rhinosinusitis. In addition, the fifteen patients with diabetes mellitus were already on medications and their blood sugar also controlled. Treatment of underlying causes of acanthosis nigricans may prevent its development and usually results in its resolution ${ }^{21}$.

There were thirteen $(5.04 \%)$ patients with the history of having used oral contraceptive pills for average of 4 months. None of these patients showed evidence of acanthosis nigricans on their skin. The reason for these could actually be as a result of short term usage or because they had stopped the usage of the medication for an average period of 3 years 8 months

\section{REFERENCES}

1 Schwartz R.A. Acanthosis nigricans. J Am Acad Dermatol 1994; 31:1-19.

2 Burke J.P., Hale D.E., Hazuola H.P. and Stern M.P. A quantitative scale of acanthosis nigricans. Diabetes care 1992, 22: 1655 - 1658.

3 Stuart C.A., Driscoll M.S., Lundquist K.F., Gilkison C.R., Shaheb S. and Smith M.M. Acanthosis nigricans. J. Basic Clin Physiol Pharmacol 1998; 9: 407 - 418.

4 Stuart C.A., Gilkison C.R. and Smith M.M. Acanthosis nigricans as a risk factor for non-insulin dependent diabetes mellitus. Clin Pediatr (Phila) 1998; 37: 73 - 79 .

5 Alberta S.K., Robert L.W., Melissa S., Andrew L.S. and Robert L.R. Acanthosis Nigricans and Diabetees Risk Factors: Prevalence in Young Persons Seen in Southwestern US Primary Care Practices. Ann Fam Med 2007; 5: 202 - 208.

6 Burke J.P., Duggirala R. and Hale D.E. Genetic basis of acanthosis nigricans in Mexican Americans and its association with phenotypes related to type 2 diabetes. Hum Genet 2000; 106: 467-472.

7 Hud J.A. Jr, Cohen J.B. and Wagner J.M. Prevalence and significance of acanthosis nigricans in an adult obese population. Arch Dermatol 1992; 128: 941-944. 
8 Fagot-Campagna A., Pettitt D.J., Engelgau M.M. Type 2 diabetes among North American children and adolescents: an epidemiological review and a public health perspective. J Pediatr 2000; 136: 64-72.

9 Nguyen T.T., Keil M.F., Russell D.L. Relation of acanthosis nigricans to hyperinsulinemia and insulin sensitivity in overweight African American and white children. J Pediatr 2001; 138: 474480.

10 Stuart C.A., Smith M.M., Gilkison C.R. Acanthosis Nigricans among Native Americans: an indicator of high diabetes risk. Am J Public Health 1994; 84: 1839-1842.

11 Cruz P.D. Jr, Hud J.A. Jr. Excess insulin binding to insulin-like growth factor receptors: proposed mechanism for acanthosis nigricans. Journal of Investigative Dermatology 1992; 98: 82-85.

12 Davidson M.B. Clinical implications of insulin resistance syndromes. Am J Med 1995; 99:420426.

13 Moller D.E., Flier J.S. Insulin resistance mechanisms, syndromes and implications. N Engl J Med 1991; 325:938-948.

14 Kurzrock R., Cohen P.R. Cutaneous paraneoplastic syndromes in solid tumors. Am J Med 1995; 99:662-671.

15 Stals H., Vercammen C. and Peeters C. Acanthosis nigricans caused by nicotinic acid: case report and review of the literature. Dermatology 1994; 189:203-206.
16 Ellis D.L., Kafka S.P., Chow J.C., Nanney L.B., Inman W.H. and McCadden M.E. et al. Melanoma, growth factors, acanthosis nigricans, the sign of Leser - Trelat, and multiple acrochordons. A possible role for alpha transforming growth factor in cutaneous paraneoplastic syndrome. N Engl J Med 1987; 317: $1582-1587$

17 Clarke J. Malignant acanthosis nigricans. Clin Exp Dermatol 1977; 2: 167 - 170.

18 Sabir S., James W.D. and Schuchter L.M. Cutaneous manifestations of cancer. Curr Opin Oncol 1999; 11: 139-144.

19 Yeh J.S., Munn S.E. and Plunkett T.A.: Coexistence of acanthosis nigricans and the sign of Leser-Trelat in a patient with gastric adenocarcinoma: a case report and literature review. J Am Acad Dermatol 2000; 42: $357-$ 362.

20 Kurzrock R., Cohen P.R. Cutaneous paraneoplastic syndromes in solid tumors. Am J Med 1995; 99:662 - 671.

21 Safai B., Grant J.M., Kurtz R. et al. Cutaneous manifestation of internal malignancies: Acanthosis nigricans. Int J Dermatol 1978; 17: 312 - 315.

22 Mukhtar Q., Cleverley G. and Voorhees R.E. et al. Prevalence of acanthosis nigricans and its association with hyperinsulinemia in New Mexico adolescents. J Adolesc Health 2001; 28: 372-376

23 Kihiczak N.I., Leevy C.B. and Krysicki M.M. Cutaneous signs of selected systemic diseases. Am J Med 1999; 30: 3-12. 